\title{
Reproductive consequences of environment-driven variation in Adélie penguin breeding phenology
}

\author{
Louise Emmerson*, Rhonda Pike, Colin Southwell \\ Department of Sustainability, Environment, Water, Population and Communities, Australian Antarctic Division, \\ Channel Hwy, Kingston, Tasmania 7050, Australia
}

\begin{abstract}
Adélie penguins Pygoscelis adeliae exhibit phenological variability across their geographic range due to fixed and variable forcing factors acting differentially on populations. Shifts in breeding phenology can be indicative of environmental change when cues for breeding initiation are tightly linked with environmental conditions. Adélie penguins on opposite sides of Antarctica display contrasting trends in clutch initiation dates, with different explanations of underlying causes. To make comparisons possible with a third significant Adélie penguin population region, we examined temporal trends and driving factors of breeding phenology at Béchervaise Island in East Antarctica. We have extended existing knowledge by examining how phenological dates are related throughout a breeding season, as well as the reproductive consequences of phenological variation. In contrast to other sites, we saw no evidence at this site of shifts towards early or delayed arrival or clutch initiation. Arrival, clutch initiation dates and the length of the incubation period had different environmental forcing factors, which explained up to $36 \%$ of the temporal variability. Penguins had a reduced courtship and egg-lay period when their arrival was delayed, and this led to later clutch initiation, later parent departure for foraging trips and later chick hatch. The phenological variations recorded here were not detrimental to chick-rearing. In particular, a delay in the start of breeding activities did not result in poor reproductive success. This indicates the importance of other factors for chick survival. Inter-annual phenological variability at this location is compared with that at other locations to further develop the colony latitude-breeding phenology relationship for Adélie penguins.
\end{abstract}

KEY WORDS: Breeding phenology · Breeding success · Colony latitude · Adélie penguins • Environmental influences

Resale or republication not permitted without written consent of the publisher

\section{INTRODUCTION}

To make the most of the short Antarctic summer, the Adélie penguin Pygoscelis adeliae commences breeding early in spring when sea ice is at its maximal extent. This enables the species to breed and undergo annual moult before the onset of winter (Lishman 1985). Increased day length initiates breeding, which is followed by a pre-migratory hyperphagia and migration toward colonies (Ainley 2002). Differences in arrival times between colonies is in part due to latitudinal differences in photoperiod and the influence of this factor on breeding initiation. It is also due to subsequent environmental conditions, penguin body condition and the interaction between the two (Ainley 2002, Barbraud \& Weimerskirch 2006). While earlier breeding can result in higher reproductive success for penguins (Reilly \& Cullen 1981, Croxall 1984, Cullen et al. 2009) and other seabirds (Spear \& Nur 1994, Frederiksen et al. 2004, Votier et al. 2009), Adélie penguins reportedly fare worse if they arrive too early or too late in relation to the population norm (Davis 1982). In this regard, the demographic consequences of variation in breeding 
phenology are a product of the advantages and disadvantages of early versus late arrival or egg-lay, and the degree of between-bird synchrony within a population.

Phenological timing is driven broadly by physiological (e.g. egg development), ecological (e.g. environmental conditions) and behavioural (e.g. decision to come ashore) processes and, typically, the interaction among these. For many species the timing of breeding activities is a response to environmental cues prior to the breeding season (Frederiksen et al. 2004), with sustained environmental changes leading to shifts towards early or delayed breeding (Visser \& Both 2005). Of concern is the potential for phenological changes to result in a mistiming between birds and their food supply, particularly during the critical offspring provisioning period (Visser \& Both 2005, Parmesan 2006, Dickey et al. 2008, Forcada et al. 2008, Forcada \& Trathan 2009). Adélie penguins breed during the austral summer when the sea ice retreats and ice-free breeding sites become available. Males arrive at the colony, establish territories and build nests, a process followed by courtship when females arrive. After egg-lay the female forages in the waters around the colony, returning up to several weeks later to switch incubation duties with the male (Sladen 1958). Newly hatched and very young chicks require regular feeding and constant parental care; this is the guard period. They can later be left unguarded (during the crèche period), while both parents forage for the chick and for self-maintenance (Clarke et al. 2006). Compared with other penguin species, Adélie penguins are considered to have a short, highly synchronous breeding cycle that is largely fixed from year to year, even though differences may exist between populations (Ainley 2002).

Relatively synchronised phenology in Antarctic seabirds is considered an adaptive response to short periods of favourable conditions, at least early in the breeding season (Croxall 1984). Hence, the highlatitude-breeding Adélie penguins are more synchronous and have a less flexible phenology than their more northerly distributed gentoo counterparts (Croxall 1984, Forcada \& Trathan 2009, Lynch et al. 2009). One possible benefit of synchronised phenology is that the arrival of males followed a few days later by females, enables rapid pair establishment and egg-lay and minimises the length of the male fast. Males who arrive early fast longer unless their partner also arrives early (Davis 1988), a factor that can increase the incidence of nest abandonment (Davis \& McCaffrey 1986), because fasting is ener- getically expensive (Johnson \& West 1973, Clarke et al. 2006). There is evidence that, later in the breeding season, earlier-hatching chicks fare poorly because of increased predation (Davis \& McCaffrey 1986); these can benefit from being in large aggregations, or crèches (Wilson 2009), which is most likely to occur when crèching is synchronous. However, there can also be disadvantages to highly synchronous breeding, such as the inability to adapt to environmental variability, rendering these species vulnerable to a changing environment (Reed et al. 2009).

It is unclear what changes in breeding phenology are detrimental to Adélie penguin reproductive attempts or whether they have the capacity to adjust their phenology in response to delayed or early arrival, or egg-lay, to ensure that their chicks fledge and that the parents are able to moult before the reformation of extensive winter sea-ice. In addition, it is unclear how much variation in the timing of breeding between birds in relation to the population norm (i.e. degree of synchrony) is detrimental to reproductive success. In this investigation we examined the links between environmental conditions (marine, local weather and broad climatic indices) and the inter-annual variability in the timing of Adélie penguin arrival, clutch initiation and length of the incubation period at Béchervaise Island, East Antarctica over a 16 yr period. We examined whether timing of arrival determined the timing of breeding phenology for the rest of the breeding season, whether timing has a detrimental effect on reproductive success and whether there is evidence that penguins adjust their phenology in response to early or late starts to breeding activities. We further examined the consequences of between-year variability and within-year synchrony in arrival and clutch initiation dates upon penguin reproductive success and whether any trends in phenology could be discerned over the 16 yr period. Finally, we compared betweenyear variability for this population with that of other studies to further our understanding of breeding phenology variation in relation to breeding-site latitude.

\section{METHODS}

The Adélie penguin population at Béchervaise Island has been monitored annually since the 1990/ 1991 split-year breeding season as part of the Commission for the Conservation of Antarctic Marine Living Resources (CCAMLR) Ecosystem Monitoring Program (SC-CAMLR 1997). Béchervaise Island is 
situated $\sim 2 \mathrm{~km} \mathrm{NW}$ of Mawson Station in East Antarctica $\left(67^{\circ} 35^{\prime} \mathrm{S}, 62^{\circ} 49^{\prime} \mathrm{E}\right)$ and has 2000 Adélie penguin breeding pairs divided among 18 subcolonies (Kerry et al. 2000). Phenological parameters in this study include dates of arrival, clutch initiation, female departure for the first foraging trip (FFT), male departure for the second foraging trip (SFT), chick hatch, chick crèche and chick fledge. Because not all parameters were monitored every year, there exist some gaps in the data set and these are described below. Most parameters, however, were measured in each of the $16 \mathrm{yr}$ between 1990/1991 and 2005/2006. Some parameters included additional years through until 2008/2009.

Breeding phenology dates were recorded from direct observation, with additional arrival dates from automated detection gateways (for details see Kerry et al. 1993). Each year since 1990/1991, up to 300 chicks and 100 adults were injected subcutaneously with glass-coated passive transponders (TIRIS, Texas Instruments; details of procedure in Clarke \& Kerry 1998), which made possible the detection of birds as they crossed the gateway. Penguin access to 2 of the larger sub-colonies and several smaller ones was restricted to crossing over one of 2 gateways by low fences constructed around the sub-colonies.

\section{Breeding phenology}

\section{Arrival}

Two measures of arrival data were used: (1) the average arrival date and the associated spread of arrival dates among birds in each year, and (2) the very first arrival date in each year. Arrival data, obtained for 10 out of $16 \mathrm{yr}$, were acquired by counting penguin abundance at the colony on an almost daily basis from the first arrival until a decline in counts indicated the end of the main arrival period and we could identify the peak arrival period. The number of penguins arriving each day was taken as the difference between counts on consecutive days. If a count was missed on a particular day, it was interpolated from counts on either side of that day. In several years, counts were conducted infrequently or began too late; these years were excluded from analysis. We collected arrival data for the entire population for 1995/1996, 1997/1998-1999/2000, 2001/ 2002-2004/2005, 2007/2008 and 2008/2009.

The first arrival date in each year could be determined from manual counts or from the first detection of a bird with an implanted tag from the automated detection gateways. In years when the field teams arrived late, only data from the automated detection gateways could be used. In years when both methods could be used, arrival dates from both methods were checked against one another. Because these had good correspondence, we are confident that the firstarrival date recorded from the automated detection gateway is reliable.

Female departure, male departure, chick hatch, chick crèche and chick fledge

Nest observations were conducted daily from the date when the first egg was laid in the colony (midNovember) until the first egg hatched, and from that point, twice daily until all chicks had crèched (early February). This involved checking nests in 2 of the larger sub-colonies (referred to as study subcolonies) for (1) the presence of an adult, (2) the adult's sex and (3) the presence of eggs and chicks. In the study sub-colonies, tagged adults known to be males were marked with Nianzol D dye solution (black) and those known to be females with diluted picric acid (yellow). The dye lasted on the penguins until moult.

Nest observations were conducted annually from $1990 / 1991$ to $2005 / 2006$ for 66 to 264 nests in the study sub-colonies, depending on year. The dates that individuals on each study nest underwent the following events were recorded: (1) clutch initiation, (2) departure of female (or male in case of reverse incubation) on FFT, (3) departure of male (or female) on SFT, (4) hatching of first egg in a nest and (5) crèching of first chick in each nest. We did not include a male departure date for those nests where the male abandoned the nest prior to the female's return. Data from successful reverse incubations were included. In 1994/1995 no chicks crèched; for 1995/1996 crèche dates are not available due to logistic difficulties.

Chicks were counted across the island every few days from the time they crèched until they fledged or until the field teams departed. Here we interpret chick departure from the island as the fledging date. In some years, field teams left early and were unable to record fledging dates. Dates when chicks were visibly preparing for departure were noted and chick counts were examined for a sudden reduction in numbers, indicating fledging. The island was also searched for dead chicks to ensure that changes were not due to mortality. The number of chicks departing between counts was determined and a 
peak fledging period identified. Fledging dates were available for 13 out of the $16 \mathrm{yr}$. They were unavailable in 1994/1995, 2004/2005 and 2005/2006 because no chicks survived. Because the end of the fledging period was often missed, it did not make sense to calculate an SD of fledging dates.

\section{Length of incubation period}

The length of the incubation period was calculated from the number of days between the departure of the adults on the FFT and chick hatch for each nest. A mean incubation period was calculated from these values for each year.

\section{Breeding success}

Breeding success was calculated as the number of crèching chicks divided by the number of occupied nests in each year. Island-wide counts of nests and chicks were conducted on or around December 2 and January 30, respectively, during each breeding season. Breeding success ranged from 0 to 2 , with 1.2 representing, for example, an average of 1.2 chicks reaching crèche age per nest. Breeding success data were available for the entire study period from 1990/1991 through 2008/2009.

\section{Environmental covariates}

We used an extensive set of environmental covariates to explore their potential influence on arrival dates, clutch initiation dates and length of the incubation period. Three types of covariates were considered: (1) local weather conditions, as measured at the nearby Mawson Station, (2) marine environmental conditions within several hundred $\mathrm{km}$ of Béchervaise Island and (3) broad climatic indices. The analysis was exploratory in that it wasn't clear a priori which covariates were most likely to influence breeding phenology or what was the magnitude of their influence. Arrival dates were assumed to be influenced by environmental conditions $6 \mathrm{wk}$ prior to the birds' arrival (from September 14 to October 27), a factor which could in turn influence bird condition and breeding site accessibility. Clutch initiation dates were considered to be related to variables influencing the birds' breeding condition prior to egg follicle development ( $\sim 3 \mathrm{wk}$ prior to egg-lay, corresponding to the period relevant to arrival; Astheimer
\& Grau 1985), or to the conditions at the colony between arrival and clutch initiation (from 28 October to 16 November). The length of incubation was thought to be influenced only by the conditions at the colony during incubation (from November 20 to December 25).

\section{Local weather conditions}

Local weather conditions were obtained and recorded from Mawson Station weather records. These included: air temperature (mean and maximum), wind speed, wind direction, and number of days with moderate to heavy snowfall or snow blow. Mean values were calculated for the arrival, clutch initiation and incubation periods (except for the number of snow days, for which a total number of days, instead of a mean, was determined). Because wind direction varied from 122 to $154^{\circ}$, calculation of a mean direction was appropriate because it did not span the sector including due north. Data were obtained from the Australian Antarctic Data Centre and the Australian Bureau of Meteorology.

\section{Marine environmental conditions}

The amount of sea ice over which penguins traverse or navigate their way around to access their breeding site has a potential impact on arrival times at the breeding site. Ice conditions may also affect their foraging ability, which in turn affects their breeding condition. Mean values for sea ice were calculated over the arrival period for the area between 60 and $65^{\circ} \mathrm{E}$, which, based on winter migratory patterns, is where Béchervaise Island penguins are found prior to the breeding season (Clarke et al. 2003). Two sea-ice parameters were calculated: (1) the areal extent of ice of $>15 \%$ sea-ice concentration (SIC) from the coastline out to $66.75^{\circ} \mathrm{S}$ (nearshore ice), previously used to represent the fast-ice area (Emmerson \& Southwell 2008); and (2) the corresponding area of ice in the off-shore region, which comprises predominantly pack ice (off-shore ice).

The final marine environmental parameter was mean sea surface temperature (SST) across a $1^{\circ}$ grid near Béchervaise Island (centred at $65^{\circ} 30^{\prime} \mathrm{S}$, $\left.62^{\circ} 30^{\prime} \mathrm{E}\right)$, measured in October. SIC data were obtained from the National Snow and Ice Data Center (NSIDC; Cavalieri et al. 1996) and SST data from the National Center for Atmospheric Research (NCAR). 
Broad climatic conditions

Broad-scale indices of the Antarctic climate include the Southern Oscillation Index (SOI) and the Southern Annular Mode (SAM). The SOI, which is calculated from the monthly or seasonal fluctuations in the air pressure difference between Tahiti and Darwin, is used to quantify the strength of an El Niño/La Niña Southern Oscillation (ENSO) event. In the area relevant to this study, positive values are associated with decreased temperatures around the Antarctic coastline between 20 and $90^{\circ} \mathrm{E}$ (Kwok \& Comiso 2002). The SAM is a dominant atmospheric circulation pattern of the Southern Ocean with positive phases indicating stronger than normal westerly winds around the Antarctic Peninsula (Arrigo et al. 2008) and colder air between 20 and $90^{\circ} \mathrm{E}$ in autumn, inducing a large sea-ice cover (Lefebvre \& Goosse 2005). The average value of SAM and SOI was calculated for the winter and early spring months (from August through to October). SOI was obtained from the Australian Bureau of Meteorology, and SAM from the Climate Prediction Center at the National Oceanic and Atmospheric Administration (NOAA).

\section{Data analysis}

Breeding phenology dates were standardised across years to days from October 1. For each year and breeding phenology event, Kolmogorov-Smirnov tests were used to test for a departure from a Gaussian distribution, with p-values calculated using the Dallal and Wilkinson approximation to the Lilliefors method (Motulsky 1999). Differences between seasonal variances associated with each phenological event were examined using Bartlett's test for equal variances. Because, during some years, data for each event were not normally distributed ( $p<0.05)$, interannual differences for each breeding phenology event were analysed using the non-parametric KruskalWallis test.

Pearson correlation analyses were used to test the association between median arrival, clutch initiation, female departure, male departure, chick hatch and chick crèche dates with lines of best fit determined for statistically significant correlations from linear regression. The interval between the arrival and clutch initiation dates was calculated, and the mean values regressed against median arrival date to determine whether the length of the courtship and clutch initiation period changed in relation to arrival dates.
Using the method of Zuur et al. (2009), no evidence appeared of autocorrelation or complex variance structures for arrival and clutch initiation dates with time lags of up to $5 \mathrm{yr}$. An information-theoretic approach was used to determine environmental covariates associated with the timing of penguin arrival and clutch initiation as well as the length of the incubation period. Linear models were fitted in $\mathrm{R}$ (version 2.10.0, R Development Core Team) and models ranked using Akaike's Information Criterion, $\triangle \mathrm{AICC}$, and AICc weights ( $w_{i ;}$ Burnham \& Anderson 2002), using the small-sample-size correction. $\triangle \mathrm{AICC}$ values for each model were calculated as the difference between each model's AICc and the minimum AICc value. Models with $\triangle \mathrm{AICc} \leq 2$ are considered strongly plausible, those with $3 \leq \Delta \mathrm{AICc} \leq 7$ are considered less plausible and those with $\triangle \mathrm{AICC} \geq 10$ are considered improbable (Burnham \& Anderson 2002). The percent deviance of the null model explained by each candidate model was determined by the difference between the null and candidate models' deviances divided by the null model's deviance. Models with 2 covariates were constructed for pairwise covariate combinations, which explained more than $10 \%$ of the deviance except when the covariates were broad climatic indices, as these are assumed to influence penguins only through influencing local environmental conditions, and, as such, should not be included in the model with other covariates.

We were also interested in whether delays or early starts to the breeding season have an adverse impact on the penguin's reproductive behaviour, and used Pearson correlation analyses to test the association between the median arrival and clutch initiation dates and breeding success. To examine whether within-year synchrony between birds influences reproductive outcome, we calculated the SD for each year for each phenological event and correlated these with breeding success. This value represents the variability in days around each breeding phenology event and could therefore be used to compare breeding events occurring at different times within a particular breeding season.

\section{RESULTS}

The earliest recorded Adélie penguin arrival at Béchervaise Island was October 1 (in 2001; Fig. 1a). Across the years, the first arrival date was October 18 $\pm 5.7 \mathrm{~d}$, and the median arrival date was November 1 $\pm 2.8 \mathrm{~d}$ (means $\pm \mathrm{SD} ; \mathrm{n}=13$ ). There were $22 \mathrm{~d}$ between the first recorded arrival date (October 1 in 

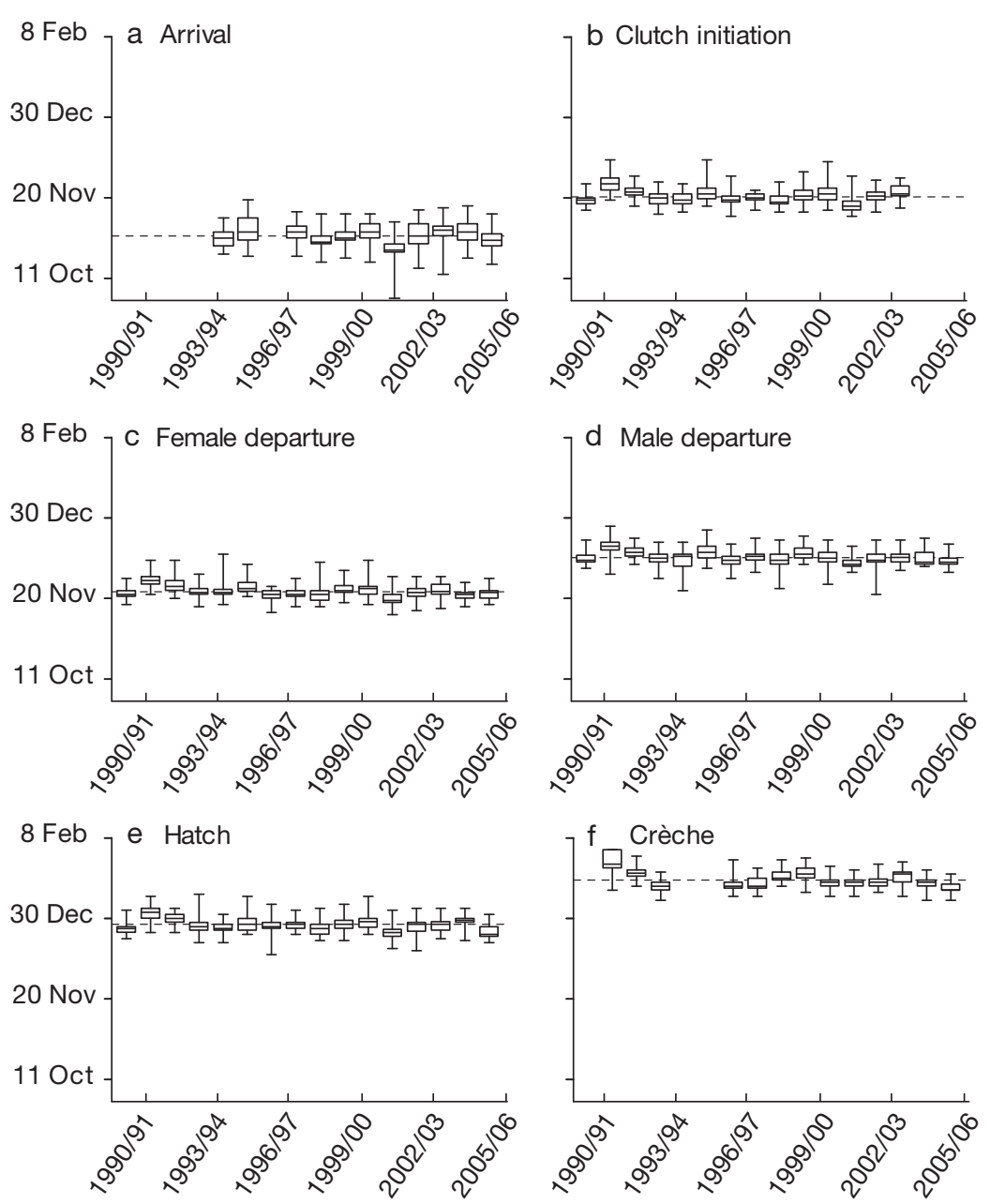

Fig. 1. Pygoscelis adeliae. (a-f) Phenological breeding dates for Adélie penguins at Béchervaise Island during study years. Dashed lines: average median values across all years; Boxes: seasonal 50th, 25th and 75th percentiles, with whiskers extending to maximum and minimum values

2001) and the latest first arrival date (October 22 in 1994).

Clutches were initiated within a few weeks of the penguins' arrival, with a mean median date of November $20 \pm 2.6$ d (Fig. 1b). Females typically departed for the FFT within a week of laying the first egg. The mean median departure date, November $22 \pm 3.0 \mathrm{~d}$ (Fig. 1c), was $\sim 3 \mathrm{wk}$ after arrival. The mean median male departure date for the SFT was December $9 \pm 2.9 \mathrm{~d}$ (Fig. 1d). Overall mean median hatch date was December $25 \pm 3.0$ d (Fig. 1e), with the earliest hatching in 1994 and 1998 (December 8), and the latest in 1992 (January 10). The mean median crèche date was January $16 \pm 4.1 \mathrm{~d}, 76 \mathrm{~d}$ after arrival (Fig. 1f). Chick fledge began around February 10 with a mean first fledging date of February 15 and the mean median date of February 24. Fledging was generally finished by March 6 .
Except for crèching dates, which showed high variability from year to year, there was greater between-bird variability within a given year than between years for all phenological dates (Table 1). The crèche period was the most variable out of all phenological events examined (Fig. 1a-1f), with the median crèche dates varying by up to $13 \mathrm{~d}$ between years. The variability between median dates for all other events was $\sim 10 \mathrm{~d}$ between years. The intra-annual variability was largest for arrival dates, that is, the spread of dates for bird arrival was greater than for other breeding phenology events (Table 1). Despite this, the SD of the means across years was similar to that of other breeding events and lower than that obtained for crèche dates.

A later arrival date at the breeding site was associated with later clutch initiation (linear correlation: $r=0.91$, $\mathrm{p}=0.0006, \mathrm{n}=9$; slope estimate: $\alpha=$ $0.58 \pm 0.11 ;$ Fig. 2a), later female departure on the FFT $(\mathrm{r}=0.73, \mathrm{p}=$ $0.01, \mathrm{n}=11, \alpha=0.40 \pm 0.13)$, later male departure on the SFT ( $\mathrm{r}=0.71, \mathrm{p}=$ $0.02, \mathrm{n}=11, \alpha=0.34 \pm 0.17)$ and later hatching $(\mathrm{r}=0.89, \mathrm{p}<0.01, \mathrm{n}=11, \alpha=$ $0.57 \pm 0.15)$. Using the slope coefficients $(\alpha)$ from the regressions suggests that a delay of a week in arrival would delay hatch by $\sim 4 \mathrm{~d}$. However, the effect of late arrival did not persist through to the median chick crèche date $(\mathrm{r}=0.13, \mathrm{p}=$ $0.74, \mathrm{n}=9$ ) or fledge date $(\mathrm{r}=0.20, \mathrm{p}=0.55, \mathrm{n}=7$ ). In years when birds arrived later, the interval between arrival and clutch initiation was reduced $(\mathrm{r}=0.83, \mathrm{p}=$ 0.006, $\mathrm{n}=9$; Fig. 2b). Courtship length varied from 17 to $22 \mathrm{~d}$.

Penguin arrival dates were most closely associated with maximum air temperature and near-shore ice extent in the $6 \mathrm{wk}$ prior to their arrival (36 and 35\% of the deviance respectively, with 22 and $20 \%$ probabilities of being the best models in the candidate set; Table 2a). Birds arrived later when near-shore ice was extensive (Fig. 3a) and maximum air temperatures were lower (Fig. 3b). Because maximum air temperature was negatively correlated with near-shore ice extent $(\mathrm{r}=-0.71, \mathrm{p}=0.01, \mathrm{n}=12)$, we did not include these 2 parameters simultaneously in a single model. A model combining 2 covariates (maximum air tem- 

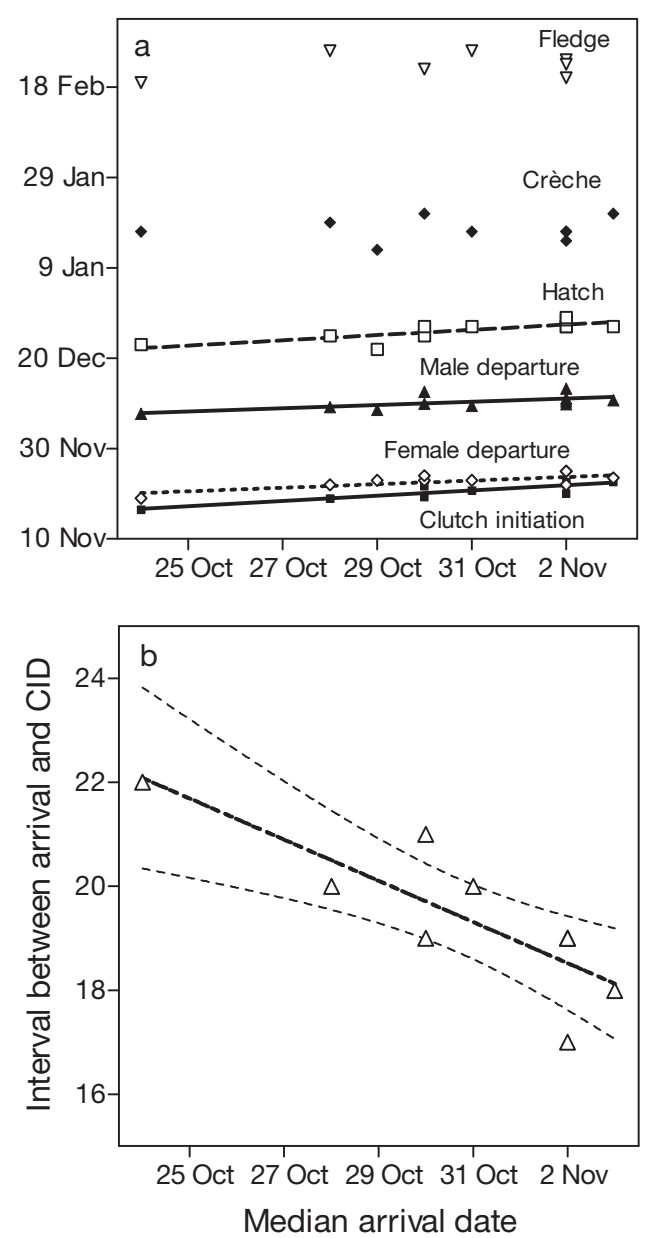

Fig. 2. Pygoscelis adeliae. Correlations: (a) between median arrival dates and median dates of subsequent phenological breeding events over $11 \mathrm{yr}$, including regression lines for statistically significant correlations; (b) between interval in days from median arrival to median clutch initiation dates plotted against median arrival dates. Light dashed lines in (b): $95 \%$ CI associated with line of best fit; CID: clutch initiation date

perature and wind speed) was also well supported, explaining $59 \%$ of the variance (Table 2a), although the principle of parsimony would suggest that there was no reason to prefer this model over either of the other 2 with just a single parameter.

The most-supported models for clutch initiation dates included the SAM, the maximum air temperature between arrival and clutch initiation and a model including wind direction and maximum air temperature (Table $2 \mathrm{~b}$ ). These models explained 25, 17 and $26 \%$ of the models' deviance respectively. Positive phases of SAM were associated with earlier clutch initiation dates, and more southerly winds with later clutch initiation (Fig. 3c,d). The incubation period (mean $\pm \mathrm{SD}=33.4 \pm 1.7 \mathrm{~d}$ ) was longer

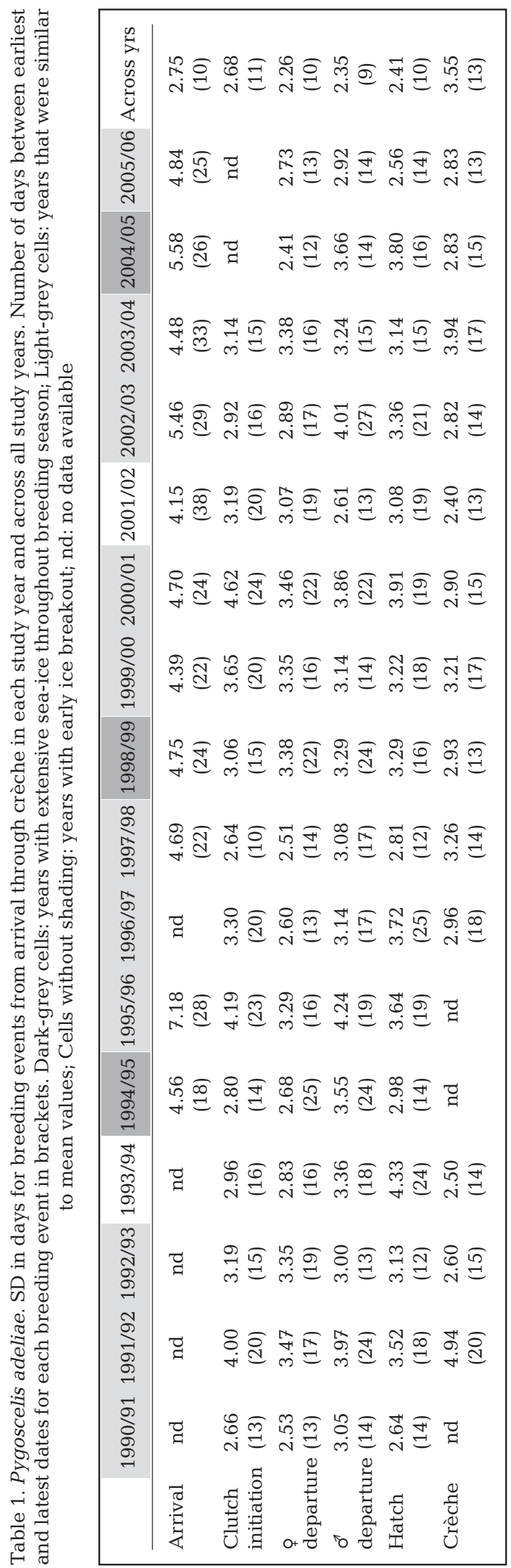


Table 2. Pygoscelis adeliae. Information-theoretic analysis results examining the association between 3 Adélie penguin phenological events with selected environmental conditions. Models ranked in order of Akaike weights ( $\left.w_{i}\right)$, and those with substantial support $(\triangle \mathrm{AICC}<2)$ are shown in bold. $\log (\mathrm{L})$ : maximised log-likelihood of the model; $\mathrm{K}$ : number of estimated parameters; AICc: selection criterion; $\triangle \mathrm{AICc}$ : difference between the model's AICc and the minimum AICc score; \% DEV: percent deviance explained by each model; Slope: sign of association; A: arrival; CID: clutch initiation; I: incubation; SOI: Southern Oscillation Index; SST: sea surface temperature

\begin{tabular}{|c|c|c|c|c|c|c|c|}
\hline Candidate models & $\log (\mathrm{L})$ & K & $\mathrm{AICc}$ & $\triangle \mathrm{AICc}$ & $w_{i}$ & $\% \mathrm{DEV}$ & Slope \\
\hline \multicolumn{8}{|l|}{ a) Arrival dates } \\
\hline A.air.temp.max & -24.61 & 2 & 58.64 & $\mathbf{0}$ & 0.22 & 36 & - \\
\hline A.near-shore.ice & -24.70 & 2 & $\mathbf{5 8 . 8 4}$ & 0.19 & 0.20 & 35 & + \\
\hline A.air.temp.max + A.wind.speed & -22.18 & 3 & 59.03 & 0.38 & 0.18 & 59 &,-+ \\
\hline Winter.spring.SAM & -26.01 & 2 & 61.45 & 2.80 & 0.05 & 17 & - \\
\hline A.wind.speed & -26.09 & 2 & 61.61 & 2.97 & 0.05 & 16 & + \\
\hline A.wind.direction & -26.67 & 2 & 62.77 & 4.13 & 0.03 & 6.7 & + \\
\hline A.off-shore.ice & -26.91 & 2 & 63.24 & 4.60 & 0.02 & 2.7 & - \\
\hline Winter.spring.SOI & -26.92 & 2 & 63.26 & 4.61 & 0.02 & 2.5 & - \\
\hline A.air.temp & -26.94 & 2 & 63.31 & 4.66 & 0.02 & 2.1 & - \\
\hline A.snowdays & -27.02 & 2 & 63.47 & 4.82 & 0.02 & 0.7 & + \\
\hline A.wind.speed + A.near-shore.ice & -24.41 & 3 & 63.48 & 4.83 & 0.02 & 38 &,++ \\
\hline Oct.SST & -27.05 & 2 & 63.54 & 4.89 & 0.02 & 0.1 & - \\
\hline \multicolumn{8}{|l|}{ b) Clutch initiation dates } \\
\hline Winter.spring.SAM & -30.80 & 3 & 70 & $\mathbf{0}$ & 0.20 & 25 & - \\
\hline CID.wind.dir & -31.56 & 3 & 71.53 & 1.53 & 0.09 & 17 & + \\
\hline CID.wind.dir + CID.air.temp.max & -30.70 & 4 & 71.85 & 1.85 & 0.08 & 26 & + \\
\hline A.near-shore.ice & -31.84 & 3 & 72.07 & 2.07 & 0.07 & 13 & + \\
\hline CID.air.temp.max & -31.94 & 3 & 72.29 & 2.29 & 0.06 & 12 & + \\
\hline Oct.SST & -32.02 & 3 & 72.45 & 2.45 & 0.06 & 11 & + \\
\hline CID.air.temp.max + Oct.SST & -30.01 & 4 & 72.46 & 2.46 & 0.06 & 33 &,++ \\
\hline A.near-shore.ice + Oct.SST & -30.08 & 4 & 72.59 & 2.6 & 0.05 & 33 &,++ \\
\hline A.off-shore.ice & -32.51 & 3 & 73.42 & 3.42 & 0.04 & 4.5 & - \\
\hline CID.wind.speed & -32.56 & 3 & 73.53 & 3.53 & 0.03 & 3.7 & - \\
\hline CID.air.temp & -32.59 & 3 & 73.59 & 3.59 & 0.03 & 3.3 & - \\
\hline Winter.spring.SOI & -32.64 & 3 & 73.69 & 3.69 & 0.03 & 2.6 & - \\
\hline CID.snowdays & -32.81 & 3 & 74.03 & 4.03 & 0.03 & 0.2 & - \\
\hline CID.wind.dir + A.wind.speed & -31.11 & 4 & 74.67 & 4.67 & 0.02 & 22 &,++ \\
\hline A.near-shore.ice + A.wind.speed & -31.28 & 4 & 75.01 & 5.01 & 0.02 & 20 &,++ \\
\hline \multicolumn{8}{|l|}{ c) Incubation period } \\
\hline I.wind.speed. & -23.53 & 3 & 55.06 & $\mathbf{0}$ & 0.28 & 26 & + \\
\hline I.snowdays. & -23.80 & 3 & 55.60 & 0.54 & 0.21 & 24 & + \\
\hline I.wind.speed + I.snowdays & -23.45 & 4 & 58.53 & 3.47 & 0.05 & 27 &,++ \\
\hline I.wind.speed + I.wind.dir & -23.50 & 4 & 58.63 & 3.57 & 0.05 & 27 &,++ \\
\hline I.air.temp & -25.47 & 3 & 58.94 & 3.88 & 0.04 & 6.1 & + \\
\hline I.wind.dir & -25.90 & 3 & 59.80 & 4.73 & 0.03 & 0.9 & - \\
\hline I.air.temp.max & -25.94 & 3 & 59.88 & 4.82 & 0.02 & 0.4 & + \\
\hline
\end{tabular}

when wind speed was higher or when snow days were more frequent during the incubation period (Table 2c). These models explained 26 and $24 \%$ of the deviance respectively, and had a 28 and $21 \%$ chance of being the best model in the candidate set.

The amount of near-shore ice adjacent to Béchervaise Island varied less between years at the start of the breeding season than later on (Fig. 4a,b, Fig. 5). The maximum difference in distance between Béchervaise Island and the nearest open water varied by $\sim 30 \mathrm{~km}$ between the most and least extensive ice conditions during the arrival period in late October and early November. For example, near-shore ice was more extensive in November 1994 (Fig. 4a) than in November 1996 (Fig. 4b). In contrast, during hatch and crèche, the near-shore ice extent varied sub- stantially from year to year (Fig. 5), as it does during fledging, immediately before ice reformation (Fig. 4c,d, Fig. 5). In some years fast-ice was completely absent during most of the chick rearing and fledging period (Fig. 4c), while in others it persisted throughout the breeding season (Fig. 4d). Peak chick hatch usually occurs when the near-shore sea-ice begins its retreat, and is generally at its minimal extent when chicks begin to fledge (Fig. 5). Nearshore ice typically begins to reform within 2 wk after peak fledging.

Average breeding success across all years was $0.64 \pm 0.31$ chicks crèched per occupied nest, varying from 0.02 chicks per nest in 1994/1995 to 1.13 chicks per nest in 1993/1994. Median arrival dates were not statistically correlated with breeding success 
$(\mathrm{r}=-0.24, \mathrm{p}=0.42, \mathrm{n}=13)$, although the highest breeding success occurred in 2001/2002, a breeding season when arrival dates were earliest. Further, the degree of synchrony of arrival dates within a breeding season was not associated with breeding success $(\mathrm{r}=-0.04, \mathrm{p}=0.90, \mathrm{n}=13)$, although the year with the highest breeding success had the least variable arrival dates. Nor was the timing of other breeding phenology events associated with reproductive success (clutch initiation: $\mathrm{r}=0.23, \mathrm{p}=0.42, \mathrm{n}=14$; female
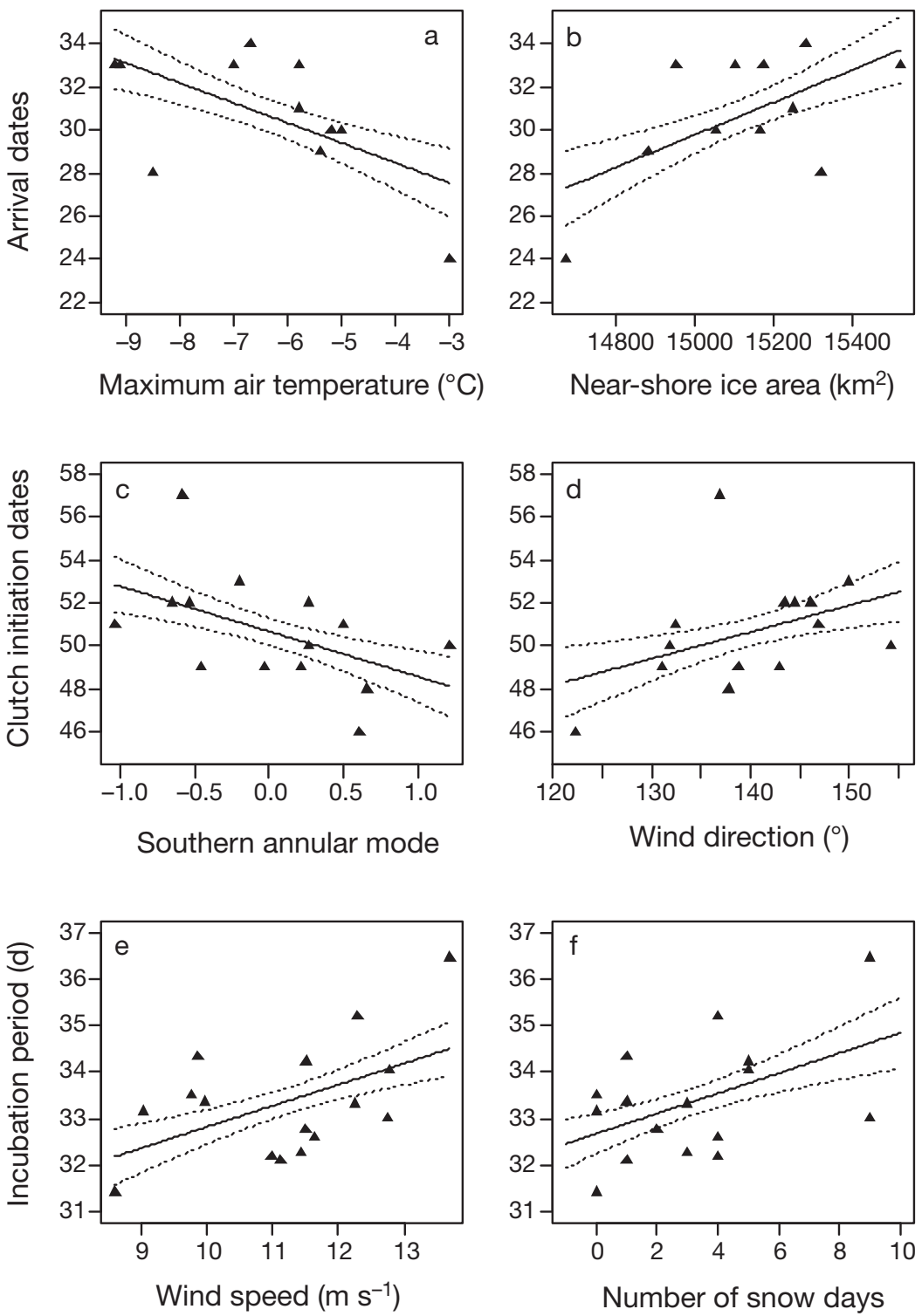

Fig. 3. Pygoscelis adeliae. Relationship between median arrival dates (calculated in days from October 1) and (a) maximum air temperature recorded in $6 \mathrm{wk}$ period prior to birds' arrival; (b) near-shore ice area. Relationship between clutch initiation dates (calculated in days from October 1) and (c) winter-spring SAM; (d) wind direction between arrival and clutch initiation. Relationship between incubation period and (e) wind speed; (f) number of snow days during incubation. Dotted lines: SE departure: $\mathrm{r}=-0.19, \mathrm{p}=0.48, \mathrm{n}=16$; male departure: $\mathrm{r}=-0.15, \mathrm{p}=0.57, \mathrm{n}=16$; hatching: $\mathrm{r}=0.06, \mathrm{p}=0.82$, $\mathrm{n}=16$; and crèching: $\mathrm{r}=-0.27, \mathrm{p}=0.38, \mathrm{n}=13$ ). A more variable spread of clutch initiation dates did not result in reduced breeding success $(r=0.04, p=0.90$, $\mathrm{n}=14)$.

The spread of first arrival dates between years at Béchervaise Island was substantial compared with other sites and across the latitudinal gradient (Fig. 6a) presented in Ainley (2002). In contrast, the spread of first clutch initiation (or egglay) dates at Béchervaise Island was not as broad as the spread of arrival dates at other sites (Fig. 6b). The Béchervaise Island dates reported here for first arrival and egg-lay are consistently later than would be expected, given the latitude of this site, and the predictions according to latitude.

No trend was noted between 1990/ 1991 and 2005/2006 for the median breeding phenology dates or for the broad sea-ice conditions or local weather conditions that were most closely associated with arrival dates (Pearson correlation: $p>0.05$ in all cases).

\section{DISCUSSION}

Birds can respond to environmental fluctuations by adjusting the timing of their annual breeding, and although phenological changes have been observed for many seabirds, the demographic consequences of these changes are less well understood. Identifying the associations between phenology, breeding success and specific environmental factors is therefore critical to understanding the mechanisms by which seabirds respond to environmental change (Reed et al. 2009). The close association between Adélie penguins and the sea-ice environment means that they encounter an environment that varies from year to year, immediately before and during the breeding season. At some locations, trends in environmental conditions are thought to contribute to the contrasting patterns in Adélie penguin breeding phenology recorded at different colonies (the pre- 
a) 4 Nov 1994

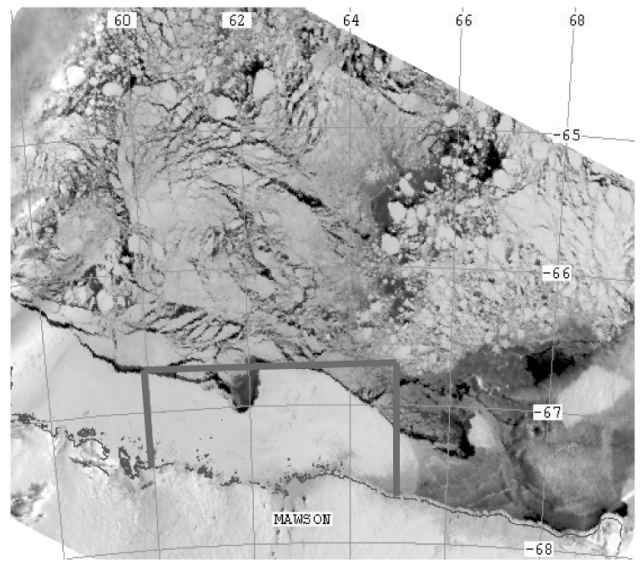

C) 28 Feb 1995

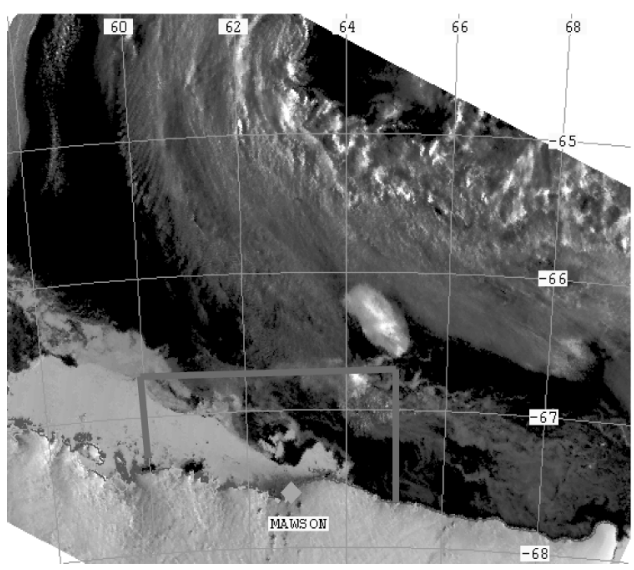

b) 4 Nov 1996

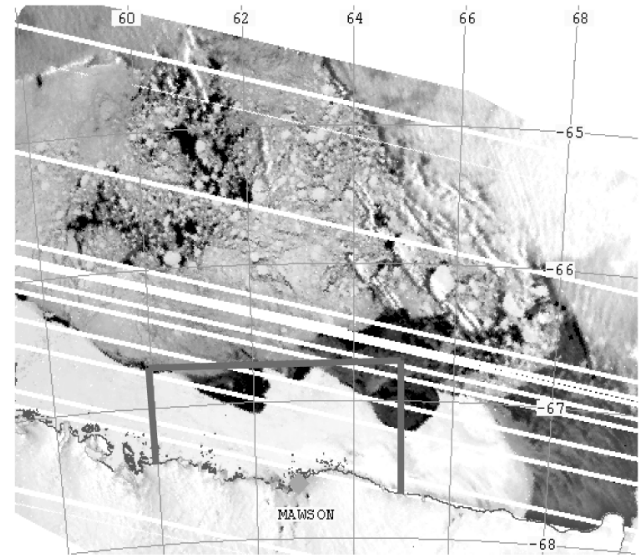

d) 3 Mar 1996

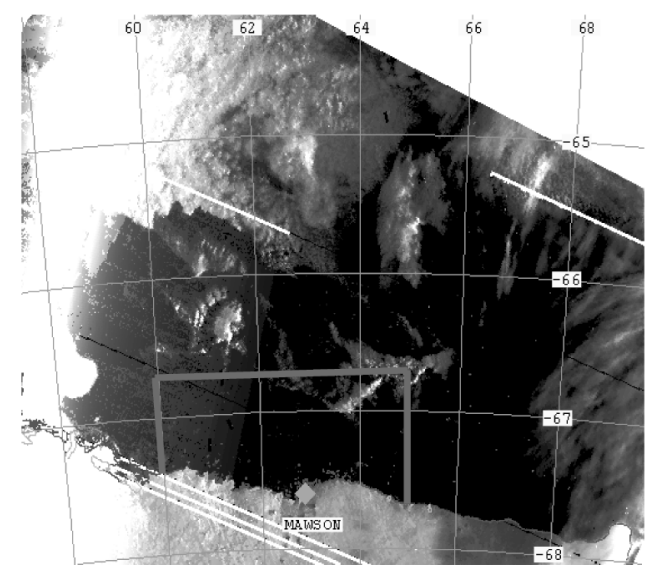

Fig. 4. Pygoscelis adeliae. Satellite images of Mawson region showing (a) extensive, (b) minimal near-shore ice cover during the arrival period, and (c) extensive (d) minimal near-shore ice during the fledging period. Images show Mawson Station ( $)$, the coastline, and the near-shore ice area (fast-ice). The grey frame is the area within which the near-shore ice area was measured according to the text

sent study, Barbraud \& Weimerskirch 2006, Lynch et al. 2009). Earlier clutch initiation associated with earlier snow melt on the Antarctic Peninsula (Lynch et al. 2009) has occurred, with a simultaneous decline in penguin populations (Trivelpiece et al. 2011), although it is unclear what contribution phenological changes make to broader demographic changes. To better understand the mechanistic processes underlying population change we examined (1) the consequences of phenological variability on the Adélie penguin's reproductive outcomes, (2) whether there were trends in phenology at this location and (3) whether variation in early stages of phenology was evident throughout the breeding cycle.

Environmental conditions can impact Adélie penguin breeding phenology directly through their influence on foraging activities, breeding site accessibility or nesting site availability. At Béchervaise Island, penguins arrived later in years with lower maximum temperatures or extensive sea-ice adjacent to the colony prior to their arrival. To some extent this was because of the increased traverse time between the fast-ice edge and the breeding colony in years with extensive ice. However, taken in isolation, an increased distance of $30 \mathrm{~km}$ between years (Fig. 4a,b, Fig. 5) could not account for the variability in arrival dates of $1 \mathrm{wk}$. This variability may instead reflect the penguins' delaying their traverse after assessing iceedge conditions, or the negative influence of extensive ice cover on prey availability. Lower maximum air temperatures may also indicate snow accumulation on the fast-ice or strong southerly katabatic winds that might slow traverse speed. Clutch initiation dates were associated with SAM and wind direction but not with snowfall, which is important for other populations (Ulbricht \& Zippel 1994, Boersma 


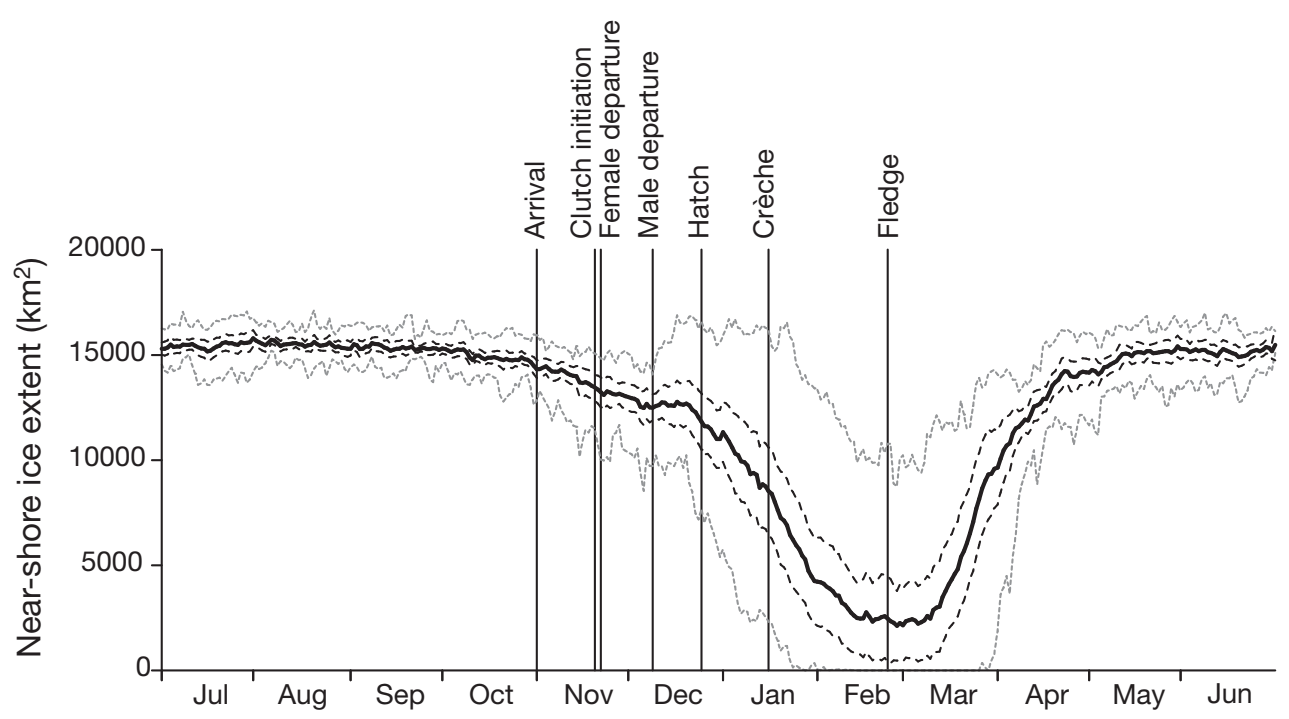

Fig. 5. Pygoscelis adeliae. Timing of mean median dates of Adélie penguin breeding phenological events across study years in relation to near-shore ice extent around Béchervaise Island, based on ice area indicated in Fig. 4. Solid line: mean nearshore ice extent across years; dark dashed line: 95\% CI; light dashed line: minimum and maximum near-shore ice extent
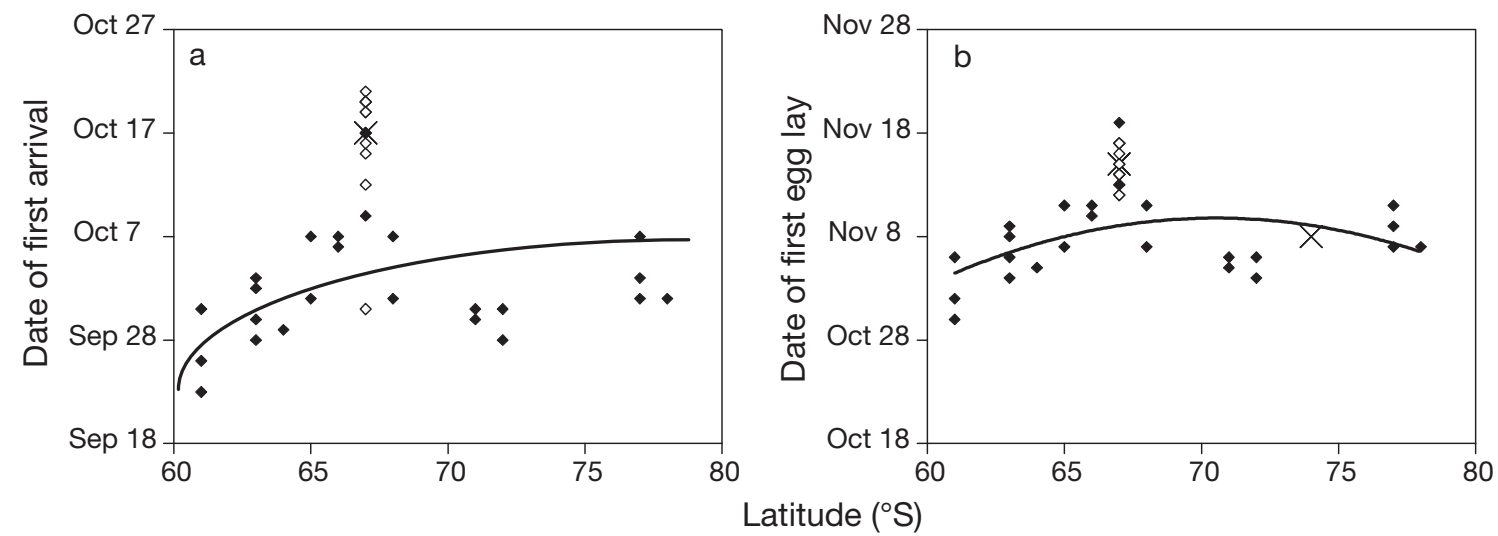

Fig. 6. Pygoscelis adeliae. Date of phenological breeding events as function of colony latitude for (a) date of first arrival; (b) date of first egg-lay. In both cases, lines reproduced from Ainley (2002). $\bullet$ : date of first arrival or egg-lay in single breeding season; $\diamond$ : date of first arrival or egg-lay on Béchervaise Island, from the present study; $\times$ : mean dates across all breeding seasons for Béchervaise Island (present study) or for Edmonson Point (based on Pezzo et al. 2007)

2008). In years with southerly winds blowing off the Mawson plateau, clutch initiation dates were later, as they were in years with positive SAM values. The difficulty with using proxies such as large-scale climatic indices is that their influence on penguin phenology is likely to be through teleconnections with local environmental conditions and as such they may not explain many important mechanistic details (Reed et al. 2009).

It is unclear whether penguins can adjust their clutch initiation dates in response to environmental conditions or whether they are driven instead by a fixed time for eggs to develop after egg follicle initia- tion. Laying dates were remarkably consistent in both this study and a study at Edmonson Point (Pezzo et al. 2007), and certainly more consistent than the arrival dates recorded here. The reduced courtship and egglay period in years with late arrival is consistent with either of 2 possibilities: (1) birds laying relatively quickly, or (2) the time it takes for the eggs to develop after a less flexible date of egg follicle initiation.

Birds are reported to delay egg-lay in response to challenging environmental conditions such as snow accumulation (Ulbricht \& Zippel 1994, Boersma 2008, Lynch et al. 2009), and the actual timing of clutch initiation is probably an interplay between physiologi- 
cal, behavioural and bird condition-driven responses. The lengthened incubation period at Béchervaise Island with stronger winds or more snow days may reflect difficulty in keeping eggs at an optimal temperature, with lower temperatures retarding egg development (de León et al. 2001). The effect of delayed or early arrival followed through into the timing of other phenophases until chick crèche.

Egg follicle development is initiated $\sim 3 \mathrm{wk}$ prior to egg-lay, when the Cape Crozier penguins are at sea (Astheimer \& Grau 1985), and around the time that Béchervaise Island birds begin their traverse to reach the colony. Parents that are unable to attain sufficient breeding condition may remain at sea and not attempt to breed (Trathan et al. 1996), or they may arrive in poor condition, with compromised immunocompetence (Moreno et al. 2001). Later egg-laying at Dumont d'Urville was attributed to poor body condition as a result of increasingly limited resources (Barbraud \& Weimerskirch 2006), although no confirmation of this was offered by measurement of penguin body mass. Emmerson et al. (2003) demonstrated previously that Béchervaise Island breeding success was reduced when females weighed less immediately after egg-laying, but was not associated with the arrival mass of the broader population. Additional factors, such as the birds' ability to attain suitable condition prior to the breeding season, almost certainly contribute to the unexplained variance in arrival and egg-lay dates.

Despite the proposition that early breeding improves seabirds' reproductive output (Frederiksen et al. 2004), we found no clear support for this at Béchervaise Island, although breeding success was particularly high in 2001/2002, when penguins arrived earlier than in other years. We suggest that for this population, factors occurring after chick hatch are more important for reproductive success than phenological timing or the breeding season length reported here. These may include the parent-chick bond, chick thermo-regulative ability and parent foraging ability (Thompson \& Emlen 1968, Ainley 2002, Clarke et al. 2006, Wilson 2009), and are certainly related to ice conditions around Béchervaise Island (Emmerson \& Southwell 2008). We do not suggest that a further reduction in the breeding period or very late starts would not be detrimental to breeding success, just that the 2 wk variability in arrival and clutch initiation dates reported here was not prohibitive of successful reproduction for this population. Additionally, there was no indication that the degree of synchrony between birds in either the timing of arrival or of egglay had significant repercussions on reproductive success. It may be useful to explore how individual breeding pairs fare in relation to phenological timing of the broader population within a given year.

In contrast to the clear shifts in Adélie penguin phenology at other sites (Barbraud \& Weimerskirch 2006, Lynch et al. 2009), there was no evidence towards earlier or later arrival or egg-lay for the Béchervaise Island penguins over the $16 \mathrm{yr}$ period considered here. Perhaps this is not surprising, given that there was no systematic trend for environmental drivers identified as being important here over the same period in this specific region. The delayed egglaying for several species over $50 \mathrm{yr}$ at Pointe-Géologie, East Antarctica (Barbraud \& Weimerskirch 2006, Zuur et al. 2009), was explained on the basis of increased difficulty in attaining suitable breeding condition as a response to decreased ice cover that in turn had caused reduced food availability. However, the more mobile cetacean populations have increased in the same area over that period (Ainley et al. 2010), a fact that may be related to their ability to better access resources. Moreover, the increase in sea-ice extent near Dumont d'Urville over the past $20 \mathrm{yr}$ (Zwally et al. 2002) is likely to affect seabird phenology and coincides with no trend in phenological dates. Hence, in contrast to the Antarctic Peninsula, no trend in phenological dates has been observed anywhere in East Antarctica over the past 20 yr. Earlier laying on the Antarctic Peninsula (Lynch et al. 2009) has occurred against a backdrop of environmental change (Trivelpiece et al. 2011), and this despite an accompanying decline in the penguins' major dietary item, Antarctic krill Euphausia superba (Atkinson et al. 2004), an event that could presumably decrease penguins' foraging ability and potentially delay phenological events. These results highlight the complex relationship between krill production and the extent, characteristics and seasonality of sea ice, which probably varies regionally (Nicol et al. 2008), making it difficult to ascertain penguins' response to sea-ice changes through direct interactions or cascading effects along trophic levels (Tanton et al. 2004, Barbraud \& Weimerskirch 2006).

Shorter day-length in spring at the more southern Adélie penguin colonies is thought to be responsible for a $25 \mathrm{~d}$ difference in first arrival dates over a $17^{\circ}$ latitudinal gradient with the simple phenology-latitude relationship blurred by local environmental conditions (Ainley 2002). Here we confirm that interannual variability in arrival and clutch initiation dates are driven by variable local environmental conditions. Furthermore, Adélie penguin arrival and egg-lay dates on Béchervaise Island are considerably 
later than other populations, and certainly later than would be expected based on latitude alone (Ainley 2002, Pezzo et al. 2007). Interestingly, the full temporal variability expressed at Béchervaise Island is almost as large as the temporal variability between sites across the latitudinal gradient (Fig. 6) although this could be an artifact of the limited years for which data are available for other sites. Because these penguins arrive later than other populations, their breeding period may be more constrained and this can be confirmed only by comparing fledgling and adult departure dates as well as arrival and clutch initiation dates across multiple populations.

There is concern that phenological changes could lead to a mismatch between periods when penguins must provision their chicks and when they have access to prey (Visser \& Both 2005, Forcada \& Trathan 2009, Beaulieu et al. 2010). At Béchervaise Island, prey is more accessible when the ice breaks out (Clarke et al. 2006), usually during the chickrearing period (Fig. 5). Therefore, the demographic consequences of any changes depend on whether sea ice and breeding phenology are in concert with each other and whether early or late breeding season requirements would be constrained. For example, the consequences of delayed penguin phenology at Béchervaise Island (breeding phenology shifted right in Fig. 5) will depend on whether ice reformation impacts the fledging and moulting birds' ability to begin their winter migration and ultimately their survival. Because chicks need to fledge before the reformation of the sea ice, delays in fledging of more than $2 \mathrm{wk}$ at Béchervaise Island are likely to be detrimental. In contrast, earlier hatching (breeding phenology shifted left in Fig. 5) at a time of extensive sea-ice could induce widespread chick failure (Emmerson \& Southwell 2008). While we have shown here that, at this stage at least, the lengthening sea-ice season has not been reflected in phenological changes in Adélie penguin breeding, a continued trend toward a longer ice season, associated with later ice retreat and earlier ice reformation in the Mawson region (Massom \& Stammerjohn 2010), could be problematic for the region's large Adélie penguin breeding population. Moreover, we cannot exclude the possibility of phenological changes in the Mawson region, which may become evident only with a longer time-series.

Acknowledgements. We thank the many dedicated field teams at Béchervaise Island, and especially J. Clarke, M. Tierney, L. Irvine and K. Kerry, the latter of whom initiated the penguin monitoring program. B. Raymond (Australian Antarctic Data Centre) provided daily sea-ice and SST data, and N. Adams (Australian Bureau of Meteorology) provided daily snow data. We thank the various engineers working on the project. A. Townsend wrote initial database queries. S. Nicol provided useful comments on the manuscript and $\mathrm{C}$. Barbraud offered insight on data interpretation. All procedures on penguins were approved by the Australian Antarctic Division's Animal Ethics Committee. This investigation was supported by Antarctic Science Advisory Committee project no. 2722 .

\section{LITERATURE CITED}

Ainley DG (2002) The Adélie penguin: bellwether of climate change. Columbia University press, New York, NY

Ainley D, Ballard G, Blight LK, Ackley S and others (2010) Impacts of cetaceans on the structure of Southern Ocean food webs. Mar Mamm Sci 26:482-498

Arrigo KR, van Dijken GL, Bushinsky S (2008) Primary production in the Southern Ocean, 1997-2006. J Geophys Res 113:C08004

Astheimer LB, Grau CR (1985) The timing and energetic consequences of egg formation in the Adélie penguin. Condor 87:256-268

Atkinson A, Siegel V, Pakhomov E, Rothery P (2004) Longterm decline in krill stock and increase in salps within the Southern Ocean. Nature 432:100-103

Barbraud C, Weimerskirch H (2006) Antarctic birds breed later in response to climate change. Proc Natl Acad Sci USA 103:6248-6251

Beaulieu M, Dervaux A, Thierry AM, Lazin D and others (2010) When sea-ice clock is ahead of Adélie penguins' clock. Funct Ecol 24:93-102

Boersma PD (2008) Penguins as marine sentinels. Bioscience 58:597-607

Burnham KP, Anderson DR (2002) Model selection and multimodel inference: a practical information-theoretic approach, 2nd edn. Springer, New York, NY

Cavalieri D, Parkinson C, Gloersen P, Zwally HJ (1996) Sea ice concentrations from Nimbus-7 SMMR and DMSP SSM/I passive microwave data (1990-2007). National Snow and Ice Data Center, Boulder, CO

Clarke J, Kerry K (1998) Implanted transponders in penguins: implantation, reliability, and long-term effects. J Field Ornithol 69:149-159

Clarke J, Kerry K, Fowler C, Lawless R, Eberhard S, Murphy R (2003) Post-fledging and winter migration of Adélie penguins Pygoscelis adeliae in the Mawson region of East Antarctica. Mar Ecol Prog Ser 248:267-278

> Clarke J, Emmerson L, Otahal P (2006) Environmental conditions and life history constraints determine foraging range in breeding Adélie penguins. Mar Ecol Prog Ser 310:247-261

Croxall JP (1984) Seabirds. In: Laws RM (ed) Antarctic ecology, Vol 2. Academic Press, New York, p 533-619

Cullen JM, Chambers LE, Coutin PC, Dann P (2009) Predicting onset and success of breeding in little penguins Eudyptula minor from ocean temperatures. Mar Ecol Prog Ser 378:269-278

> Davis LS (1982) Timing of nest relief and its effect on breeding success in Adélie penguins Pygoscelis adeliae. Condor 84:178-183

Davis LS (1988) Coordination of incubation routines and mate choice in Adélie penguins Pygoscelis adeliae. Auk 105:428-432 
Davis LS, McCaffrey FT (1986) Survival analysis of eggs and chicks of Adélie penguins Pygoscelis adeliae. Auk 103: 379-388

de León A, Soave GE, Ferretti V, Moreno J (2001) Factors that affect hatching asynchrony in the chinstrap penguin (Pygoscelis antarctica). Polar Biol 24:338-342

Dickey MH, Gauthier G, Cadieux MC (2008) Climatic effects on the breeding phenology and reproductive success of an arctic-nesting goose species. Glob Change Biol 14:1973-1985

Emmerson L, Southwell C (2008) Sea ice cover and its influence on Adélie penguin reproductive performance. Ecology 89:2096-2102

Emmerson L, Clarke J, Kerry K, Southwell C (2003) Temporal variability and the interrelationships between CEMP parameters collected on Adélie penguins at Béchervaise Island. CCAMLR Science 10:75-90

- Forcada J, Trathan PN (2009) Penguin responses to climate change in the Southern Ocean. Glob Change Biol 15: 1618-1630

Forcada J, Trathan PN, Murphy EC (2008) Life history buffering in Antarctic mammals and birds against changing patterns of climate and environmental variation. Glob Change Biol 14:2473-2488

Frederiksen M, Harris MP, Daunt F, Rothery P, Wanless S (2004) Scale-dependent climate signals drive breeding phenology of three seabird species. Glob Change Biol 10:1214-1221

Johnson SR, West GC (1973) Fat content, fatty acid composition and estimates of energy metabolism of Adélie penguins Pygoscelis adeliae during the early breeding season fast. Comp Biochem Physiol B 45:709-719 Medline

Kerry KR, Clarke JR, Else GD (1993) The use of an automated weighing and recording system for the study of the biology of Adélie penguins (Pygoscelis adeliae). Proc NIPR Symp Polar Biol, Tokyo 6:62-75

Kerry K, Meyer L, Papps W, Clarke J, Irvine L (2000) Béchervaise Island, MacRobertson Land, Antarctica, CCAMLR ecosystem monitoring program (CEMP) monitoring site: description, maps and colony photographs. CCAMLR Sci Abstracts No. WG-EMM-00/32, p 9

Kwok R, Comiso JC (2002) Southern ocean climate and sea ice anomalies associated with the southern oscillation. J Clim 15:487-501

> Lefebvre W, Goosse H (2005) Influence of the Southern Annular Mode on the sea ice-ocean system: the role of the thermal and mechanical forcing. Ocean Science 1: 145-157

Lishman GS (1985) The comparative breeding biology of Adélie and Chinstrap penguins Pygoscelis adeliae and $P$. antarctica at Signy Island, South Orkney Islands. Ibis 127:84-99

Lynch HJ, Fagan W, Naveen R, Trivelpiece SG, Trivelpiece WZ (2009) Timing of clutch initiation in Pygoscelis penguins on the Antarctic Peninsula: towards an improved understanding of off-peak census correction factors. CCAMLR Science 16:149-165

Massom RA, Stammerjohn SE (2010) Antarctic sea ice change and variability: physical and ecological implications. Polar Sci 4:149-186

Moreno J, Potti J, Yorio P, Borboroglu PG (2001) Sex differences in cell-mediated immunity in the Magellanic penguin Spheniscus magellanicus. Ann Zool Fenn 38:111-116
Motulsky H (1999) Analyzing data with GraphPad Prism. GraphPad Software, San Diego, CA

> Nicol S, Worby T, Leaper R (2008) Changes in the Antarctic sea ice ecosystem: potential effects on krill and baleen whales. Mar Freshw Res 59:361-382

Parmesan C (2006) Ecological and evolutionary responses to recent climate change. Annu Rev Ecol Syst 37:637-669

Pezzo F, Olmastroni S, Volpi V, Focardi S (2007) Annual variation in reproductive parameters of Adélie penguins at Edmonson Point, Victoria Land, Antarctica. Polar Biol 31:39-45

> Reed TE, Warzybok P, Wilson AJ, Bradley RW, Sarah Wanless S, Sydeman WJ (2009) Timing is everything: flexible phenology and shifting selection in a colonial seabird. J Anim Ecol 78:376-387

Reilly PN, Cullen JM (1981) The little penguin Eudyptula minor in Victoria, II: Breeding. Emu 81:1-19

SC-CAMLR (1997) CCAMLR Ecosystem Monitoring Program: standard methods for monitoring studies. Convention on the Conservation of Antarctic Marine Living Resources (CCAMLR), Hobart, Australia

Sladen WJL (1958) The pygoscelid penguins: I. Methods of study II. The Adélie penguin, Report No. 17, Falkland Islands Dependencies Survey Scientific Reports, HMSO, London

Spear L, Nur N (1994) Brood size, hatching order and hatching date: effects on 4 life-history stages from hatching to recruitment in western gulls. J Anim Ecol 63:283-298

Tanton JL, Reid K, Croxall JP, Trathan PN (2004) Winter distribution and behaviour of gentoo penguins Pygoscelis papua at South Georgia. Polar Biol 27:299-303

Thompson D, Emlen J (1968) Parent-chick individual recognition in the Adélie penguin. Antarct J US 3:132

Trathan PN, Croxall JP, Murphy EJ (1996) Dynamics of Antarctic penguin populations in relation to interannual variability in sea ice distribution. Polar Biol 16: 321-330

> Trivelpiece WZ, Hinke JT, Miller AK, Reiss CS, Trivelpiece SG, Watters G (2011) Variability in krill biomass links harvesting and climate warming to penguin population changes in Antarctica. Proc Natl Acad Sci USA 108: 7625-7628 Medline

> Ulbricht J, Zippel D (1994) Delayed laying and prolonged fasting in Adélie penguins Pygoscelis adeliae. Polar Biol 14:215-217

Visser ME, Both C (2005) Shifts in phenology due to global climate change: the need for a yardstick. Proc Biol Sci 272:2561-2569 Medline

Votier SC, Hatchwell BJ, Mears M, Birkhead TR (2009) Changes in the timing of egg-laying of a colonial seabird in relation to population size and environmental conditions. Mar Ecol Prog Ser 393:225-233

Wilson D (2009) Causes and benefits of chick aggregations in penguins. Auk 126:688-693

Zuur AF, Barbraud C, Ieno EN, Weimerskirch H, Smith GM, Walker NJ (2009) Estimating trends for Antarctic birds in relation to climate change. In: Zuur AF, Ieno EN, Walker NJ, Saveliev AA, Smith GM (eds) Mixed effects models and extensions in ecology with R. Springer, New York, NY, p 343-362

Zwally HJ, Comiso JC, Parkinson CL, Cavalieri DJ, Gloersen P (2002) Variability of Antarctic sea ice 1979-1998. J Geophys Res 107:3041-3059 